\title{
Improved Whole-Genome Sequence of Phytophthora capsici Generated by Long-Read Sequencing
}

\author{
Jinxia Shi, ${ }^{1}$ Wenwu Ye, ${ }^{2}$ Dongfang $M a,{ }^{3}$ Junliang Yin, ${ }^{3}$ Zhichao Zhang, ${ }^{2}$ Yuanchao Wang, ${ }^{2}$ \\ and Yongli Qiao ${ }^{1, \dagger}$ \\ ${ }^{1}$ Shanghai Key Laboratory of Plant Molecular Sciences, College of Life Sciences, Shanghai Normal \\ University, Shanghai 200234, China \\ ${ }^{2}$ Department of Plant Pathology, Nanjing Agricultural University, Nanjing, Jiangsu 210095, China \\ ${ }^{3}$ College of Agriculture, Yangtze University, Jingzhou 434025, China
}

\begin{abstract}
The soilborne oomycete Phytophthora capsici is the most destructive pathogen of vegetable crops and is responsible for substantial economic losses worldwide. Here, we present an improved genome assembly of $P$. capsici generated by Oxford Nanopore long-read sequencing (for de novo assembly) and Illumina short-read sequencing (for polishing). The genome of $P$. capsici is $100.5 \mathrm{Mb}$ in length (GC content $=50.8 \%$ ) and contains 26,069 predicted protein-coding genes. The whole genome of $P$. capsici is assembled into 194 scaffolds, $90 \%$ of which are larger than $300 \mathrm{~kb}$. The $\mathrm{N}_{50}$ scaffold length and maximum scaffold length are 1.0 and $4.1 \mathrm{Mb}$, respectively. The wholegenome sequence of $P$. capsici will broaden our knowledge of this pathogen and enhance our understanding of the molecular basis of its pathogenicity, which will facilitate the development of effective management strategies.
\end{abstract}

\section{Genome Announcement}

Phytophthora capsici is an important oomycete phytopathogen that causes foliar blight, damping-off, wilting, and root, stem, and fruit rot in many vegetable crops such as lima bean (Phaseolus lunatus), tomato (Solanum lycopersicum), snap bean ( $P$. vulgaris), eggplant ( $S$. melongena), cucurbits, and pepper (Capsicum annum) (Lamour et al. 2012a). Phytophthora capsici was first reported in New Mexico by Fabián García, then systematically described and isolated from chile pepper in New Mexico by Leon H. Leonian in 1922 (Barchenger et al. 2018; Granke et al. 2012). Since its discovery, $P$. capsici has caused severe disease epidemics in North, Central, and South America as well as in Europe and Asia, resulting in serious economic losses worldwide. Although diseases caused by $P$. capsici represent a significant threat to the commercial cultivation of vegetable crops, current management strategies are based on the implementation of cultural practices, application of chemicals, and development of resistant cultivars (Hausbeck and Lamour 2004). More importantly, P. capsici is difficult to control because its thick-walled oospores remain dormant for a long period of time. Moreover, $P$. capsici shows rapid adaptation to fungicides and new hosts because of the significant mitotic loss of heterozygosis and many sexual progeny in field isolates

${ }^{\dagger}$ Corresponding author: Y. Qiao; qyl588@gmail.com

J. Shi, W. Ye, and D. Ma contributed equally to this work.

The author(s) declare no conflict of interest.

Accepted for publication 15 March 2021.

\section{Funding}

This work was supported by grants from the National Natural Science Foundation of China (32072502), the "Shuguang Program" of Shanghai Education Development Foundation and Shanghai Municipal Education Commission (18SG43), the Science and Technology Commission of Shanghai Municipality (18DZ2260500), and the Next Generation Bio-Green 21 Program (PJ015782), Rural Development Administration, Republic of Korea to Y. Qiao; and by a grant from the National Natural Science Foundation of China (31972250) to W. Ye.

\section{Keywords}

genome assembly, long-read sequencing, Phytophthora capsici, plant pathogen 
Table 1. Overview of the genome assembly statistics of nine Phytophthora capsici isolates ${ }^{a}$

\begin{tabular}{|c|c|c|c|c|c|c|c|c|c|}
\hline Genomic features & SD33 & LT263 & LT1534 & CPV-219 & CPV-262 & CPV-267 & CPV-270 & CPV-277 & CPV-302 \\
\hline Genome size (Mb) & 100.5 & 95.2 & 64.0 & 58.9 & 40.8 & 52.2 & 58.3 & 53.4 & 56.9 \\
\hline $\begin{array}{l}\text { Number of } \\
\text { scaffolds }\end{array}$ & 194 & 424 & 917 & 7,580 & 11,754 & 11,832 & 8,363 & 9,341 & 9,277 \\
\hline $\mathrm{N}_{50}$ length $(\mathrm{kb})$ & $1,013.4$ & 313.0 & 706.0 & 14.1 & 4.6 & 6.6 & 11.6 & 9.4 & 10.0 \\
\hline GC content $(\%)$ & 50.8 & ND & 51.0 & 49.9 & 50.0 & 49.9 & 49.9 & 49.9 & 49.9 \\
\hline $\begin{array}{l}\text { BUSCO- } \\
\text { completeness (\%) }\end{array}$ & 94.0 & 97.0 & 91.0 & 91.5 & 72.6 & 82.9 & 89.8 & 91.0 & 93.2 \\
\hline $\begin{array}{l}\text { Number of protein- } \\
\text { coding genes }\end{array}$ & 26,069 & 19,391 & 19,805 & 25,102 & 19,275 & 23,579 & 25,004 & 23,404 & 24,322 \\
\hline $\begin{array}{l}\text { Number of predicted } \\
\text { RxLR effectors }\end{array}$ & 640 & 357 & ND & 379 & 263 & 341 & 371 & 350 & 353 \\
\hline $\begin{array}{l}\text { Number of predicted } \\
\text { CRN effectors }\end{array}$ & $59+170$ & $29+70$ & ND & 230 & 121 & 183 & 213 & 181 & 187 \\
\hline Source of strain & $\begin{array}{l}\text { Capsicum } \\
\text { annuum }\end{array}$ & $\begin{array}{l}\text { Cucurbita } \\
\text { pepo }\end{array}$ & $\begin{array}{l}\text { Cucurbita } \\
\text { pepo }\end{array}$ & $\begin{array}{l}\text { Capsicum } \\
\text { pubescens }\end{array}$ & $\begin{array}{l}\text { Cucurbita } \\
\text { pepo }\end{array}$ & $\begin{array}{l}\text { Cucurbita } \\
\text { pepo }\end{array}$ & $\begin{array}{l}\text { Capsicum } \\
\text { annuum }\end{array}$ & $\begin{array}{l}\text { Capsicum } \\
\text { annuum }\end{array}$ & $\begin{array}{l}\text { Capsicum } \\
\text { chinense }\end{array}$ \\
\hline Reference & This study & $\begin{array}{l}\text { Cui et al. } \\
2019\end{array}$ & $\begin{array}{l}\text { Lamour } \\
\text { et al. } \\
2012 a\end{array}$ & $\begin{array}{l}\text { Reyes- } \\
\text { Tena } \\
\text { et al. } \\
2019\end{array}$ & $\begin{array}{l}\text { Reyes- } \\
\text { Tena } \\
\text { et al. } \\
2019\end{array}$ & $\begin{array}{l}\text { Reyes- } \\
\text { Tena } \\
\text { et al. } \\
2019\end{array}$ & $\begin{array}{c}\text { Reyes- } \\
\text { Tena } \\
\text { et al. } \\
2019\end{array}$ & $\begin{array}{l}\text { Reyes- } \\
\text { Tena } \\
\text { et al. } \\
2019\end{array}$ & $\begin{array}{l}\text { Reyes- } \\
\text { Tena } \\
\text { et al. } \\
2019\end{array}$ \\
\hline
\end{tabular}

${ }^{\mathrm{a}} \mathrm{ND}=$ not described.

(Hulvey et al. 2010; Lamour et al. 2012b; Lyon et al. 2016; Zhu et al. 2020). Compared with other Phytophthora spp. (Wang et al. 2011; Wang et al. 2019; Whisson et al. 2016), the molecular mechanisms underlying the pathogenicity of $P$. capsici and its interactions with host plants remain poorly described and characterized.

Several different versions of the $P$. capsici genome sequence have been recently released publicly, based on two isolates collected from the United States (Lamour et al. 2012a; Cui et al. 2019) and six isolates collected from Mexico (Reyes-Tena et al. 2019). However, given its complex genome and life history, the genome assembly of $P$. capsici remains challenging, and a high-quality reference genome of $P$. capsici is unavailable. In addition, no genome sequence has been documented for the $P$. capsici strain isolated from China. To broaden our current knowledge of $P$. capsici and to manipulate the molecular basis of its rapid adaptation and high pathogenicity, additional genome resources are needed. These resources will also help to control Phytophthora blight in pepper. Here, we report an improved whole-genome sequence of $P$. capsici strain SD33 with fewer contigs.

$P$. capsici strain SD33, the predominant stain in Shandong (one of the main chili pepper production areas in China), was originally isolated in 2006 from lesions on the leaves of chili pepper plants in Shandong province. Strain SD33 was maintained on rye agar medium supplemented with $2 \%$ sucrose, and genomic DNA was extracted from hyphae using DNeasy Plant Mini Kit (Qiagen). The genome of SD33 was sequenced by Oxford Nanopore sequencing at Biomarker Technologies Co., Ltd. (Beijing, China). The genome of strain SD33 was sequenced at $116 \times$ coverage, generating $11.6 \mathrm{~Gb}$ of high-quality long-read sequences (clean reads), with a mean length of $36.5 \mathrm{~kb}$ and $\mathrm{N}_{50}$ length of $27.7 \mathrm{~kb}$. The reads were de novo assembled using Canu v1.5 (Koren et al. 2017) and polished using Pilon v1.22 (Walker et al. 2014) by mapping Nanopore clean reads and Illumina short reads (obtained in parallel; 6.9 $\mathrm{Gb}, 150$-bp paired-end reads) on to the preassembled genome. The final genome assembly was $100.5 \mathrm{Mb}$ in length and contained 194 scaffolds, $90 \%$ of which were larger than 300 $\mathrm{kb}$ in size. The $\mathrm{N}_{50}$ scaffold length and maximum scaffold length were 1.0 and $4.1 \mathrm{Mb}$, respectively, and the GC content was $50.8 \%$. Compared with the most recently released $P$. capsici LD263 genome assembly, the $P$. capsici SD33 genome assembly was larger in size by 5.6\% (100.5 versus $95.2 \mathrm{Mb}$ ) (Table 1) (Lamour et al. 2012a). Additionally, compared with the LD263 genome assembly, the number of contigs in the SD33 genome assembly was reduced by $45.8 \%$ (194 versus 424), and the $\mathrm{N}_{50}$ scaffold length was increased by 3.2 -fold (1,013.4 versus $313.0 \mathrm{~kb}$ ) (Lamour et al. 2012a). The completeness of the SD33 assembly was calculated against the "alveolata_stramenophiles_ensembl" database using benchmarking universal single-copy orthologs (BUSCO) v2.0 (Simão et al. 2015). Of 234 complete BUSCOs, 220 (94.0\%) were identified (single-copy = 168, 71.8\%

Vol. 34, No. 7, $2021 / 867$ 

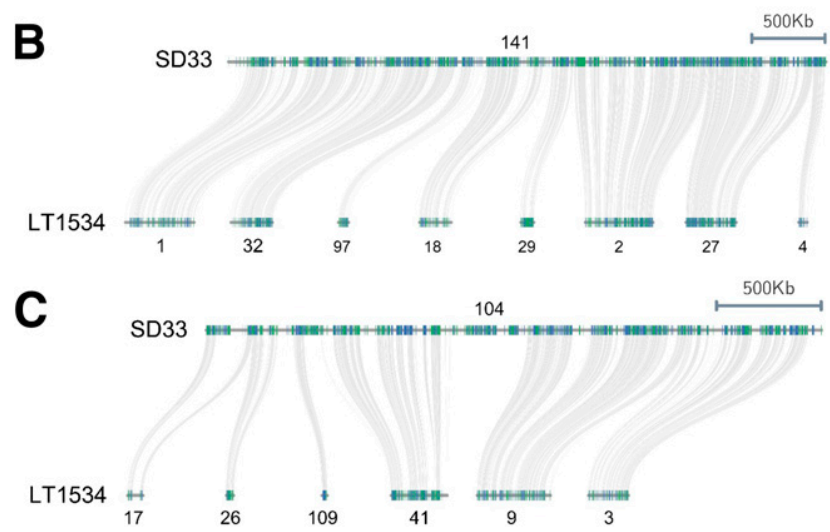

Fig. 1. Gene synteny between the SD33 and LT1534 assemblies was analyzed using MCscan (Python version) (Tang et al. 2008). A, Landscape of all scaffolds which contain any genes showing collinearity (98.4\% of SD33 assemblies) and B and C, two examples of the largest scaffolds in SD33 assemblies.

and duplicate $=52,22.2 \%)$, with only two fragmented $(0.9 \%)$ and 12 missing $(5.1 \%)$ BUSCOs. The assembly completeness was also evaluated by mapping with Illumina short reads, which showed that $93.1 \%$ of all reads were mapped accurately.

Repetitive elements identified by RepeatMasker v4.0.6 (Tarailo-Graovac and Chen 2009) accounted for $36.2 \%$ of the whole-genome sequence. Among these repetitive elements, $27.3 \%$ were class I (retrotransposons), and $6.4 \%$ were class II (DNA transposons). Protein-coding genes were identified by ab initio methods using Augustus v2.4 (Stanke and Waack 2003), Genescan v1.0 (Burge and Karlin 1997), GlimmerHMM v3.0.4 (Majoros et al. 2004), GenelD v1.4 (Alioto et al. 2018), and SNAP v2006-7-28 (Korf 2004), and by homology-based methods using GeMoMa v1.3.1 (Keilwagen et al. 2016). Then, the data obtained were integrated with EVM v1.1.1 (Haas et al. 2008). In total, 26,069 protein-coding genes were identified, with a mean gene length and coding sequence length of 1,762.7 and $1,385.1 \mathrm{bp}$, respectively, and an average intron number of 1.74 per gene. Among the protein-coding genes, 25,889 (99.3\%) could be annotated using the Pfam (15,268, 58.6\%), Gene Ontology (11,261, 43.2\%), Kyoto Encyclopedia of Genes and Genomes (6,547, $25.1 \%)$, euKaryotic Orthologous Groups $(9,863,37.8 \%)$, Swiss-Prot $(9,487,36.4 \%)$, TrEMBL $(13,991,53.7 \%)$, or NCBI nonredundant protein $(25,885,99.3 \%)$ databases. In addition, analysis using SignalP v3.0 (Bendtsen et al. 2004) and TMHMM v2.0 (Krogh et al. 2001) showed that 2,352 proteins $(9.0 \%)$ containing a signal peptide but no transmembrane helix composed the candidate secretome. In addition, 640 RxLR and 59 CRN (170 others may code CRNlike proteins or pseudogenes) effector-encoding genes were predicted. Macrosynteny and local synteny were accomplished by MCscan (Python version) (Tang et al. 2008). A preliminary synteny analysis revealed an overall gene collinearity between the SD33 and LT1534 assemblies, and showed an expansion in SD33 assemblies with more continuous and detailed genomic sequences. These sequences may include those previously unassembled using short sequencing reads (e.g., repetitive elements, and tandem repeated genes or genome fragments) and those absent in the LT1534 assemblies (Fig. 1).

Overall, the $P$. capsici strain SD33 genome sequence assembly presented in this study will serve as a valuable resource for investigating blight, crown and root rot, and fruit rot diseases caused by $P$. capsici, identifying its novel virulence factors and effectors, and elucidating the molecular mechanisms underlying its high pathogenicity and rapid adaptation. Moreover, this new genomic resource will facilitate comparative genomic analysis of plant pathogens. 


\section{Data Availability}

The whole-genome sequence data reported in this article have been deposited in the Genome Warehouse in the National Genomics Data Center (National Genomics Data Center Members and Partners et al. 2020), Beijing Institute of Genomics (China National Center for Bioinformation), Chinese Academy of Sciences, under accession number GWHAZID00000000, and are publicly accessible online.

\section{Author-Recommended Internet Resource}

Accession number GWHAZID00000000: https://ngdc.cncb.ac.cn/gwh

\section{Literature Cited}

Alioto, T., Blanco, E., Parra, G., and Guigó, R. 2018. Using geneid to identify genes. Curr. Protoc. Bioinf. 64:e56.

Barchenger, D. W., Lamour, K. H., and Bosland, P. W. 2018. Challenges and strategies for breeding resistance in Capsicum annuum to the multifarious pathogen, Phytophthora capsici. Front. Plant Sci. 9:628.

Bendtsen, J. D., Nielsen, H., von Heijne, G., and Brunak, S. 2004. Improved prediction of signal peptides: SignalP 3.0. J. Mol. Biol. 340:783-795.

Burge, C., and Karlin, S. 1997. Prediction of complete gene structures in human genomic DNA. J. Mol. Biol. 268:78-94.

Cui, C., Herlihy, J. H., Bombarely, A., McDowell, J. M., and Haak, D. C. 2019. Draft assembly of Phytophthora capsici from long-read sequencing uncovers complexity. Mol. Plant-Microbe Interact. 32:1559-1563.

Granke, L. L., Quesada-Ocampo, L., Lamour, K., and Hausbeck, M. K. 2012. Advances in research on Phytophthora capsici on vegetable crops in the United States. Plant Dis. 96:1588-1600.

Haas, B. J., Salzberg, S. L., Zhu, W., Pertea, M., Allen, J. E., Orvis, J., White, O., Buell, C. R., and Wortman, J. R. 2008. Automated eukaryotic gene structure annotation using EVidenceModeler and the program to assemble spliced alignments. Genome Biol. 9:R7.

Hausbeck, M. K., and Lamour, K. H. 2004. Phytophthora capsici on vegetable crops: Research progress and management challenges. Plant Dis. 88:1292-1303.

Hulvey, J., Young, J., Finley, L., and Lamour, K. 2010. Loss of heterozygosity in Phytophthora capsici after N-ethyl-nitrosourea mutagenesis. Mycologia 102:27-32.

Keilwagen, J., Wenk, M., Erickson, J. L., Schattat, M. H., Grau, J., and Hartung, F. 2016. Using intron position conservation for homology-based gene prediction. Nucleic Acids Res. 44:e89.

Koren, S., Walenz, B. P., Berlin, K., Miller, J. R., Bergman, N. H., and Phillippy, A. M. 2017. Canu: Scalable and accurate long-read assembly via adaptive k-mer weighting and repeat separation. Genome Res. 27:722-736.

Korf, I. 2004. Gene finding in novel genomes. BMC Bioinf. 5:59.

Krogh, A., Larsson, B., von Heijne, G., and Sonnhammer, E. L. 2001. Predicting transmembrane protein topology with a hidden Markov model: Application to complete genomes. J. Mol. Biol. 305:567-580.

Lamour, K. H., Mudge, J., Gobena, D., Hurtado-Gonzales, O. P., Schmutz, J., Kuo, A., Miller, N. A., Rice, B. J., Raffaele, S., Cano, L. M., Bharti, A. K., Donahoo, R. S., Finley, S., Huitema, E., Hulvey, J., Platt, D., Salamov, A., Savidor, A., Sharma, R., Stam, R., Storey, D., Thines, M., Win, J., Haas, B. J., Dinwiddie, D. L., Jenkins, J., Knight, J. R., Affourtit, J. P., Han, C. S., Chertkov, O., Lindquist, E. A., Detter, C., Grigoriev, I. V., Kamoun, S., and Kingsmore, S. F. 2012a. Genome sequencing and mapping reveal loss of heterozygosity as a mechanism for rapid adaptation in the vegetable pathogen Phytophthora capsici. Mol. Plant-Microbe Interact. 25:1350-1360.
Lamour, K. H., Stam, R., Jupe, J., and Huitema, E. 2012b. The oomycete broadhost-range pathogen Phytophthora capsici. Mol. Plant Pathol. 13:329-337.

Lyon, R., Correll, J., Feng, C., Bluhm, B., Shrestha, S., Shi, A., and Lamour, K. 2016. Population structure of Peronospora effusa in the southwestern United States. PLoS One 11:e0148385.

Majoros, W. H., Pertea, M., and Salzberg, S. L. 2004. TigrScan and GlimmerHMM: Two open source ab initio eukaryotic gene-finders. Bioinformatics 20:2878-2879.

National Genomics Data Center Members and Partners, Zhang, Z., Zhao, W., Xiao, J., Bao, Y., He, S., Zhang, G., Li, Y., Zhao, G., and Chen, N. 2020. Database resources of the National Genomics Data Center in 2020. Nucleic Acids Res. 48:D24-D33.

Reyes-Tena, A., Huguet-Tapia, J. C., Lamour, K. H., Goss, E. M., RodríguezAlvarado, G., Vázquez-Marrufo, G., Santillán-Mendoza, R., and FernándezPavía, S. P. 2019. Genome sequence data of six isolates of Phytophthora capsici from Mexico. Mol. Plant-Microbe Interact. 32:1267-1269.

Simão, F. A., Waterhouse, R. M., loannidis, P., Kriventseva, E. V., and Zdobnov, E. M. 2015. BUSCO: Assessing genome assembly and annotation completeness with single-copy orthologs. Bioinformatics 31:3210-3212.

Stanke, M., and Waack, S. 2003. Gene prediction with a hidden Markov model and a new intron submodel. Bioinformatics 19:ii215-ii225.

Tang, H., Bowers, J. E., Wang, X., Ming, R., Alam, M., and Paterson, A. H. 2008. Synteny and collinearity in plant genomes. Science 320:486-488.

Tarailo-Graovac, M., and Chen, N. 2009. Using RepeatMasker to identify repetitive elements in genomic sequences. Curr. Protoc. Bioinf. Chapter 4:Unit 4.10

Walker, B. J., Abeel, T., Shea, T., Priest, M., Abouelliel, A., Sakthikumar, S., Cuomo, C. A., Zeng, Q., Wortman, J., Young, S. K., and Earl, A. M. 2014. Pilon: An integrated tool for comprehensive microbial variant detection and genome assembly improvement. PLoS One 9:e112963.

Wang, Q., Han, C., Ferreira, A. O., Yu, X., Ye, W., Tripathy, S., Kale, S. D., Gu, B., Sheng, Y., Sui, Y., Wang, X., Zhang, Z., Cheng, B., Dong, S., Shan, W., Zheng, X., Dou, D., Tyler, B. M., and Wang, Y. 2011. Transcriptional programming and functional interactions within the Phytophthora sojae RXLR effector repertoire. Plant Cell 23:2064-2086.

Wang, Y., Tyler, B. M., and Wang, Y. 2019. Defense and Counterdefense During Plant-Pathogenic Oomycete Infection. Annu. Rev. Microbiol. 73:667-696.

Whisson, S. C., Boevink, P. C., Wang, S., and Birch, P. R. 2016. The cell biology of late blight disease. Curr. Opin. Microbiol. 34:127-135.

Zhu, X., He, S., Fang, D., Guo, L., Zhou, X., Guo, Y., Gao, L., and Qiao, Y. 2020. High-throughput sequencing-based identification of Arabidopsis miRNAs induced by Phytophthora capsici infection. Front. Microbiol. 11:1094. 